\title{
A Study on Correlation of Umbilical Cord Arterial Blood pH with Perinatal Asphyxia \& Early Neonatal Outcome
}

\author{
Nutan Singh ${ }^{\oplus 1}$, Asheesh Kumar Gupta ${ }^{\circledR 2}$, Ajay Kumar Arya ${ }^{\circ 3}$ \\ ${ }^{1}$ Associate Professor, Department Of Paediatrics, Susheela Tiwari Hospital, Haldwani, Uttarakhand, India, ${ }^{2}$ Post Graduate Student, Department Of Paediatrics, Susheela \\ Tiwari Hospital, Haldwani, Uttarakhand, India, ${ }^{3}$ Professor, Department Of Paediatrics, Susheela Tiwari Hospital, Haldwani, Uttarakhand, India.
}

\section{Abstract}

Background: Perinatal asphyxia is one of the major causes of neonatal morbidity \& mortality. Asphyxia can damage almost every organ of neonate. Our purpose was to determine the correlation of cord blood $\mathrm{pH}$ with birth asphyxia \& early neonatal outcome. Subjects and Methods: A prospective study was conducted over a period of one year at STH Haldwani. We enrolled 108 term neonates with signs of fetal distress, thick MSL, non-reassuring NST \& there were subjected for estimation of umbilical cord blood pH, APGAR score, outcome looked were resuscitation needed, NICU admission, delay in feed \& encephalopathy (sarnat \& sarnat stage). Results: In our study, cord blood pH had significant correlation with perinatal asphyxia $(\mathrm{R}=-0.926)$. Area under $\mathrm{ROC}$ curved showed that mean $\mathrm{pH}<7.1(\mathrm{ROC}=0.998)$ is very significant in predicting the adverse outcome. Conclusion: Cord blood pH is very sensitive and specific \& has good correlation in predicting the birth asphyxia $\&$ adverse neonatal outcome. Measurement of cord blood $\mathrm{pH}$ is recommended in all the neonates with signs of fetal distress.

Keywords: $\mathrm{pH}$, non-stress test, Apgar score, perinatal asphyxia

Corresponding Author: Asheesh Kumar Gupta, Post Graduate Student, Department Of Paediatrics, Susheela Tiwari Hospital, Haldwani, Uttarakhand, India.

E-mail: ashish2ni@gmail.com

Received: 18 May 2020

Revised: 21 June 2020

Accepted: 2 July 2020

Published: 9 July 2020

\section{Introduction}

Perinatal asphyxia is a most common preventable cause of neurological injury in new borns \& a leading factor which significantly increases the neonatal morbidity and mortality. It is characterized by an impairment of exchange of the respiratory gases (oxygen and carbon dioxide) resulting in hypoxemia and hypercapnia, accompanied by metabolic acidosis. In response to persistent hypoxia during perinatal period and anaerobic metabolism, baby will develop acidosis. It is a multi -organ disorder affecting virtually every organ system in the body including brain, heart, lungs, kidneys and intestine. The prime concern is CNS dysfunction (Hypoxic ischaemic encephalopathy) because it is not only associated with high risk of mortality but also carries significant risk of serious long-term neuromotor sequelae. Despite the recent advances and protocols in perinatal care, Perinatal asphyxia is a leading cause of infant morbidity and mortality worldwide. Although the infant mortality due to infectious diseases have been significantly reduced but perinatal asphyxia is still one of challenging problem especially in rural population. As per latest estimates, perinatal asphyxia accounts for $9.4 \%$ (i.e.,
0.72 million) of total under 5 child mortality worldwide. Along with prematurity and systemic infections, Perinatal asphyxia is one of three most common causes of neonatal deaths. ${ }^{[1,2]}$ It is also an important cause of stillbirths and according to the National neonatal perinatal database (NNPD; 20022003), perinatal asphyxia is the commonest cause of stillbirths, accounting for $45.1 \%$ of all such cases. ${ }^{[3]}$ World Health Organization defined birth asphyxia as "the failure to initiate and sustain breathing at birth". A precise definition of birth asphyxia is given by the American College of Obstetrician and gynaecologists (ACOG), American Academy of Paediatrics (AAP) includes existence of 3 factors: Metabolic or mixed academia $(\mathrm{pH}<7)$ which is determined by umbilical cord arterial blood samples; APGAR score of $<3$ for longer than 5 min; neurological manifestations; and multisystem organ dysfunction. NNPD network define the perinatal asphyxia as; Moderate Perinatal asphyxia: slow/ gasping breathing or an APGAR score of 4 to 6 at 1 minute \& Severe Perinatal asphyxia: no breathing or an APGAR score 0-3 at 1 minute. ${ }^{[4-6]}$ 
Although perinatal asphyxia is commonly encountered diagnosis at birth, there is no common consensus regarding its definition \& various criteria has been given to label it perinatal asphyxia by WHO, NNPD, AAP \& ACOG. our study is attempted to look for any association of the umbilical cord $\mathrm{pH}$ value with perinatal asphyxia \& early neonatal outcome in neonates with signs of foetal distress. Early neonatal outcomes were measured by various parameters such as, need for resuscitation, NICU admission, neurological examination (tone, seizures \& HIE staging), delay in starting \& attaining full feed $\&$ final outcome (death/ discharge).

\section{Subjects and Methods}

This is a prospective study was carried out at susheela Tiwari hospital, Haldwani, affiliated to kumaun University Uttarakhand. One hundred eight singleton pregnant women of more than 37 weeks of gestation were included in the study from January 2018 to December 2018. Study was approved by the ethical committee and informed consents were taken from the parents. 108 neonates were studied who met the following

\section{Inclusion Criteria}

1. Singleton, live born neonates of gestational age $>37$ weeks, AGA

2. Suspected perinatal asphyxia

(a) Signs of intrapartum fetal hypoxia, as indicated by nonreassuring Non- stress test on continuous electronic fetal monitoring.

(b) Thick meconium stained liquor

(c) Apgar score of $<7$ at $1 \mathrm{~min}$ of life

(d) Need for resuscitation for $>1$ minute

\section{Exclusion Criteria}

(a) Preterm and low birth babies

(b) Multifetal gestation

(c) IUGR babies

(d) Babies with intrauterine and perinatal infections

(e) Gross congenital malformations

(f) History of maternal intrapartum fever

(g) Maternal drug addiction,

(h) Anti-epileptics use by mothers

Immediately after birth of asphyxiated new born, $1 \mathrm{ml}$ of blood was collected in heparinised syringe from doubly clamped segment of umbilical cord for ABG and another $2 \mathrm{ml}$ blood collected in EDTA vial for routine investigations. All these new-borns were shifted to NICU for further monitoring, screening and staging of HIE as per sarnat and sarnat staging. The admitted new-borns were observed for immediate outcome during 24 hours and classified as neurologically normal or abnormal on basis of presence of signs and symptoms of HIE. All the cases were followed up till discharge or death for final outcome. A detailed maternal history, APGAR score, examination \& investigation of enrolled baby was done. Outcome variables:- 1) Need for resuscitation 2) Need for NICU/Neonatal ward admission 3) Delay in attaining full feeds 4) Neurological examination 5) Death/ discharge.

Analysis was done using Statistical Package for Social Sciences (SPSS) version 21.0 and $P$ values less than 0.05 were considered statistically significant.

\section{Results}

Among 108 neonates, 61(56.48\%) were male and 47 (43.52\%) were female, $95(87.90 \%)$ were term, $9(8.33 \%)$ were postdated \& $4(3.70 \%)$ were post term. $101(93.52 \%)$ babies were delivered by vertex presentation and $7(6.48 \%)$ by breech. $84(77.78 \%)$ babies had birth weight between 2.5 $3 \mathrm{Kg}, 14.81 \%$ between $3-3.5 \mathrm{~kg} \& 7.41 \%$ babies more than 3.5Kg. 48(44.44\%) neonates were delivered normally, 60 $(55.56 \%)$ were delivered by caesarean section.15 (13.89\%) had Reassuring NST and 93 (86.11\%) had Non-Reassuring NST suggestive of fetal distress. 26 (24.07\%) neonates had Thick MSAF and in $82(75.93 \%)$ the amniotic fluid was clear. Mean APGAR score at $1 \mathrm{~min}$ was 3.27 and at $5 \mathrm{~min}$ 6.27. [Table 1]

Neonatal outcome was studied by various parameters like need for resuscitation, NICU admission, neurological abnormalities, delay in feed, and final outcome i.e. death/discharge. These babies were not followed for long term neurodevelopmental sequalae. Out of 108 studied neonates, 78 (72.2\%) needed resuscitation whereas $30(27.78 \%)$ didn't need any form of resuscitation, 77 (71.30\%) babies were admitted in NICU for care \& management as per protocols, whereas 31 $(28.70 \%)$ neonates were shifted to mother side \& followed up till dischage. In neurological examination,70 (64.81\%) neonates had normal tone, $25(23.15 \%)$ had flaccid tone \& 13 (12.04\%) showed increased tone, $72(66.67 \%)$ had no seizures while $36(33.33 \%)$ had seizures as an abnormal neurological examination finding. 52 (48.15\%) were neurologically normal without encephalopathy, $20(18.52 \%)$ were in HIE stage 1, $11(10.19 \%)$ were in stage $2 \& 25(23.15 \%)$ were in stage 3 of hypoxic ischemic encephalopathy according to sarnat $\&$ sarnat staging. Among 108 neonates, feed was started in 87 neonates, out of them $28(32.56 \%)$ had delay in attaining full feed whereas $59(67.44 \%)$ had attained feed timely. 21 neonates were too sick for feed to be started \& they ultimately died during hospital stay and $87(80.56 \%)$ babies were discharged from hospital. [Table 2] 
Correlation coefficient and $\mathrm{P}$ value was calculated for cord blood $\mathrm{pH}$ and ischemic brain injury among the newborns with hypoxic ischemic encephalopathy \& it was observed that it is statistically significant ( $p$ value $<0.001) \&$ significant negative correlation with severity of birth asphyxia. [Table $3 \&$ Figure 1]. Table 4 shows the babies with and without encephalopathy and their corresponding $\mathrm{pH}$ values.

Table 5-10 showing, neonatal morbidities in the form of need for resuscitation, NICU admission, seizure, stages of encephalopathy, delay in feed \& final outcome i.e. death/discharge with their mean $\mathrm{pH}$ values. Figure 2, shows Umbilical cord $\mathrm{pH}$ value with cut off $<7.1$ has area under ROC curve (0.998), standard error $=0.00149$, sensitivity $=96.43 \%$, specificity $=98.08 \%$, positive predictive value $=98.2 \&$ negative predictive value $=96.2$.

\begin{tabular}{ll}
\hline Table 1: Birth weight & \\
\hline Clinical variable Birth weight & Case $=108$ \\
\hline $2.5-3.0 \mathrm{~kg}$ & $84(77.78 \%)$ \\
\hline $3.1-3.5 \mathrm{~kg}$ & $16(14.81 \%)$ \\
\hline $3.5 \mathrm{~kg}$ & $8(7.41 \%)$ \\
\hline Sex & \\
\hline Male & $61(56.48 \%)$ \\
\hline Female & $47(43.52 \%)$ \\
\hline Gestation & \\
\hline Term & $95(87.96 \%)$ \\
\hline Post term and post dated & $13(12.04 \%)$ \\
\hline Mode of delivery & \\
\hline NVD & $48(44.44 \%)$ \\
\hline LSCS & $60(55.56 \%)$ \\
\hline PRESENTATION & \\
\hline VERTEX & $101(93.52 \%)$ \\
\hline BREECH & $7(6.48 \%)$ \\
\hline AMNIOTIC FLUID & \\
\hline MECONIUM STAINED & $26(24.07 \%)$ \\
\hline CLEAR & $82(75.93 \%)$ \\
\hline APGAR & 3.27 \\
\hline MEAN APGAR AT 1 MIN & 6.27 \\
\hline ME APGAR AT 5 MIN & $93(86.11 \%)$ \\
\hline NON STRESS TEST & $15(13.89 \%)$ \\
\hline NON REASSURING & \\
\hline REASUURING & \\
\hline
\end{tabular}

\begin{tabular}{|lll|}
\hline Table 2: Neonatal Outcome & & \\
\hline Resuscitation & Yes & $72.2 \%$ \\
\hline & No & $27.78 \%$ \\
\hline NICU admission & Yes & $71.30 \%$ \\
\hline \multirow{2}{*}{ Delay in feed } & No & $28.70 \%$ \\
\hline \multirow{2}{*}{ Seizures } & Yes & $32.36 \%$ \\
\hline & No & $67.44 \%$ \\
\hline Abnormal tone & Yes & $33.33 \%$ \\
\hline & No & $66.67 \%$ \\
\hline HIE & Yes & $35.19 \%$ \\
\hline & No & $64.81 \%$ \\
\hline & No HIE & $48.15 \%$ \\
\hline \multirow{2}{*}{ Final outcome } & STAGE 1 & $18.52 \%$ \\
\hline & STAGE 2 & $10.19 \%$ \\
\hline & STAGE 3 & $23.15 \%$ \\
\hline
\end{tabular}

Table 3: Correraltion Coefficient of Cord Blood PH to Preedict the Severity of Birth Asphyxia

\begin{tabular}{lll}
\hline Parameter & P value & Correraltion coefficient \\
Cord Blood $\mathrm{Ph}$ & $<0.001$ & -0.926 \\
\hline
\end{tabular}

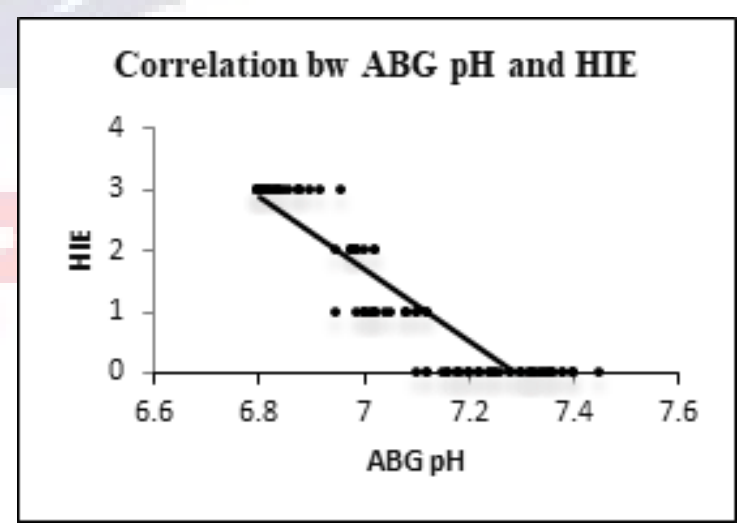

Figure 1: ?

Table 4: HIE

\begin{tabular}{lll}
\hline & 1) Not in HIE & 2) HIE \\
\hline ABG pH & & \\
Sample size & 52 & 56 \\
\hline Mean \pm Stdev & $7.28 \pm 0.08$ & $6.94 \pm 0.1$ \\
Median & 7.3 & 6.98 \\
\hline Min-Max & $7.1-7.45$ & $6.8-7.12$ \\
\hline Inter quartile Range & $7.200-7.340$ & 6.840 \\
& & 7.020 \\
\hline
\end{tabular}


Table 5: Resuscitation

\begin{tabular}{llll}
\hline Variables & No & Yes & P value \\
ABG pH & - & - & $<.0001$ \\
Sample size & 30 & 78 & \\
Mean \pm Stdev & $7.32 \pm 0.07$ & $7.02 \pm$ & \\
& & 0.16 & \\
Median & 7.32 & 7 & \\
Min-Max & $7.1-7.45$ & $6.8-7.4$ & \\
Inter quartile & $7.300-7.360$ & $6.880-$ & \\
Range & & 7.160 & \\
\hline
\end{tabular}

Table 6: NICU Admission

\begin{tabular}{llll}
\hline & No & Yes & P value \\
ABG pH & - & - & $<.0001$ \\
Sample size & 31 & 77 & \\
Mean \pm & $7.31 \pm 0.08$ & $7.02 \pm 0.16$ & \\
Stdev & & & \\
Median & 7.32 & 7 & \\
Min-Max & $7.1-7.45$ & $6.8-7.4$ & \\
$\begin{array}{l}\text { Inter quar- } \\
\text { tile Range }\end{array}$ & 7.300 & -6.880 & - \\
\hline
\end{tabular}

Table 7: Seizure

\begin{tabular}{llll}
\hline & Negative & Positive & P value \\
ABG pH & - & - & $<.0001$ \\
Sample size & 72 & 36 & \\
Mean \pm & $7.21 \pm 0.13$ & $6.89 \pm$ & \\
Stdev & & 0.08 & \\
Median & 7.22 & 6.87 & \\
Min-Max & $6.95-7.45$ & $6.8-7.02$ & \\
Inter quar- & $7.100-7.320$ & $6.820 \quad-$ \\
tile Range & & 6.980 & \\
\hline
\end{tabular}

Table 8: Delay in feed

\begin{tabular}{llll}
\hline & No & Yes & P value \\
ABG pH & - & - & $<.0001$ \\
Sample size & 58 & 28 & \\
Mean \pm & $7.25 \pm 0.11$ & $7 \pm 0.09$ & \\
Stdev & & & \\
Median & 7.28 & 7 & \\
Min-Max & $7-7.45$ & $6.8-7.22$ & \\
$\begin{array}{l}\text { Inter quar- } \\
\text { tile Range }\end{array}$ & 7.180 & -6.980 & \\
\hline
\end{tabular}

Table 9: HIE Stageand Mean Ph Values

\begin{tabular}{lll}
\hline & Case(n) & Mean pH \\
NO HIE & 52 & $7.28 \pm 0.08$ \\
HIE STAGE 1 & 20 & $7.04 \pm 0.04$ \\
HIE STAGE 2 & 11 & $6.99 \pm 0.01$ \\
HIE STAGE 3 & 25 & $6.84 \pm 0.04$ \\
\hline
\end{tabular}

Table 10: Final Outcome

\begin{tabular}{llll}
\hline & Death & Discharge & P value \\
ABG pH & - & - & \\
Sample size & 21 & 87 \\
Mean \pm Stdev & 6.84 & \pm & \\
& 0.04 & & \\
Median & 6.83 & 7.18 & \\
Min-Max & $6.8-6.96$ & $6.8-7.45$ & \\
Inter quartile & 6.810 & -7.020 \\
Range & 6.880 & 7.320 & \\
\hline
\end{tabular}

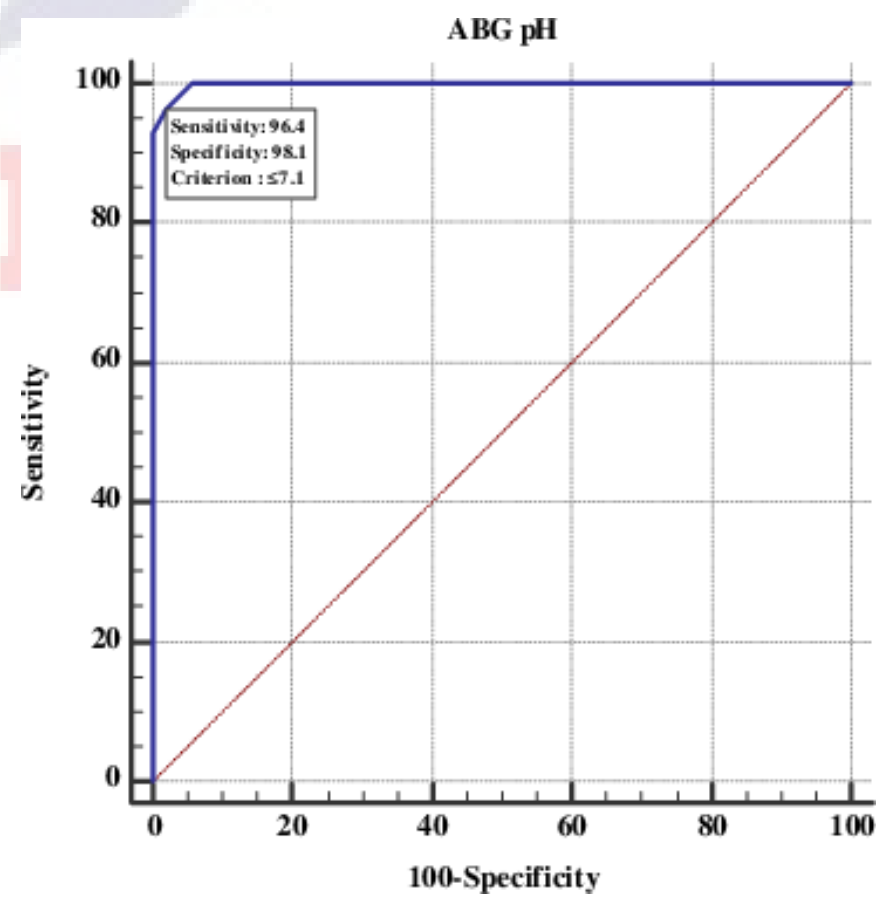

Figure 2: ROC curve for cord blood pH and birth asphyxia 


\section{Discussion}

In our study, 56(41.85\%) neonates out of 108 samples showed neurological morbidity in the form of hypoxic ischemic insult with $20(18.52)$ in HIE stage $1,11(10.2 \%)$ in HIE 2 \& $25(23.15 \%)$ cases in HIE stage 3, previous studies done by N.N. Finner and C.M. Robertson et al in their study of 33 cases, $35 \%$ were in stage- $1,50 \%$ were in stage II and $15 \%$ were in stage III and in the study by Sarnat and Sarnat et alamong 21 cases, 7 (33)cases were in Stage 1, 9 cases (43\%) were in stageII and one (5\%) case were in stage-III. ${ }^{[7,8]}$

As there is no common consensus to define the perinatal asphyxia, we used AAP \& recent NNF criteria, a pH less than 7 was considered as significant acidemia. In our study $35.48 \%$ cases had umbilical $\mathrm{pH}<7$ and $64.52 \%$ had $\mathrm{pH}>7$, similar results were observed in study by Prasanna R. et al and Goldaber and colleagues. ${ }^{[8-10]}$ In our study, Incidence of seizures was higher at $32 \%$, when compared with studies by other workers, Goodwin et al, Andres et al \& Vanderberg et al. ${ }^{[11-13]}$ Lower incidence was seen in study done by Goodwin et al (1\%), Andres (5.2\%) \& vanderberg (5.5\%) and a higher incidence $(10 \%)$ in study done by Sehdev and co-workers which correlates with our study. ${ }^{[14]}$ We observed that as the $\mathrm{pH}$ value decreases, the incidence of convulsions increases \& this finding is supported by other studies Goodwin et al, Andres et al, Perlman \& Risser et al. ${ }^{[1,12,15]}$ In present study, babies with $\mathrm{pH}>7$ had only $8 \%$ seizures while at $\mathrm{pH}$ between 6.9 to 7.0 , the incidence of convulsions were $32 \%$ which significantly increased to $60 \%$ with $\mathrm{pH}<6.9$. similar results were observed in study by Goodwin et al, the incidence of seizures was $9 \%$ in $\mathrm{pH}=6.9-6.99 \& 80 \%$ in $\mathrm{pH}$ 6.61-6.70. In our study, 78 neonates out of 108 cases needed some form of resuscitation with mean $\mathrm{pH} 7.02 \pm 0.16$ when compared to babies who didn't need resuscitation $(\mathrm{n}=30)$, mean $\mathrm{pH}$ was $7.32 \pm 0.07$, similar results had been observed in study by Mousa Ahmadpo. ${ }^{[11,16]}$

In present study, $71.3 \%$ babies needed NICU admission with mean $\mathrm{pH} 7.02 \pm 0.16$, when compared with other neonates who were shifted to mother side without any need of NICU admission with mean $\mathrm{pH} 7.31 \pm 0.08$ which was statistically significant $(\mathrm{p}<0.0001)$. Our results are supported by Ahmadpour Mousa et al who studied the factors affecting the neonatal outcomes. ${ }^{[16]} 16$ babies with $\mathrm{pH}$ less than 7.2 required NICU admission in compared to 3 babies in the other group with $\mathrm{pH}$ more than $7.2 \&$ the difference was statistically significant $(p<0.05)$. Victory et al observed that the risk for NICU admission increased with worsening of acidemia at birth in term neonates. ${ }^{[17]}$ Another study by Rogers et al, it was concluded that neonates with $\mathrm{pH}$ value $>7.02$, only $50 \%$ required resuscitation and $36.36 \%$ of cases needed NICU admission, while $100 \%$ babies required resuscitation and NICU admission at $\mathrm{pH}$ below 7.02, these results were also observed in our study. ${ }^{[18]}$ In this study there were 87 neonates in whom feed was started, 28 had delay in attaining full feeds with mean $\mathrm{pH} 7 \pm 0.09$ \& rest 59 neonates $(\mathrm{pH}=7.25 \pm 0.11)$ had attained full feed timely. 21 neonates were too sick for feed to be started \& they died ultimately during the hospital stay. P value of 0.0001 was obtained after applying Fischer exact test, which is statistically significant. Study by Mousa Ahmedpour they found similar results of $\mathrm{pH}$ with delay in starting feeds. ${ }^{[16]}$

In present study, out of 108 cases 56 babies were neurologically abnormal (HIE Stage 1, 2 \& 3) with mean $\mathrm{pH}$ value $6.94 \pm 0.1$ (median $=6.98)$ when compared with neonates without any neurological sequalae $(\mathrm{n}=52)$, mean $\mathrm{pH}$ was $7.28 \pm 0.08 \quad($ median $=7.3) \quad(\mathrm{p}<0.001)$. A meta-analysis by Gemma L Malin found that low umbilical cord arterial $\mathrm{pH}$ was significantly associated with poor neonatal outcomes. ${ }^{[19]}$ Encephalopathy (HIE 1, 2 \& 3) was closely linked with odds ratio $16.9,95 \%$ confident interval 9.7 to 29.5 in neonates with low arterial cord $\mathrm{pH}$. Study by Yeh P1 et al found that seizure within 24 hours of life was more among neonates with $\mathrm{pH}<7.1{ }^{[20]}$ Study done by Goldaber et al and Goodwin et al who worked on whether fetal acidemia indicated by low umbilical cord blood $\mathrm{pH}$ was associated with an adverse neonatal outcome. ${ }^{[10,11]}$

In our study, total 21(19.44\%) babies died \& among them 19 neonates belonged to $\mathrm{pH}$ range 6.80-6.89, two babies had $\mathrm{pH}$ value between 6.90-6.99. All the deaths were observed at $\mathrm{pH}$ below 7.0. Similar results were seen in study by Vanderberg et al, ${ }^{[13]}$ mortality was $23 \%$ at $\mathrm{pH}$ below 7.0 , whereas in other studies much less deaths were observed at $\mathrm{pH}<7$, Goldaber et $\mathrm{al}^{\left[{ }^{[10]}\right.} 5 \%$, Andres et al, ${ }^{[12]} 4.5 \%$, Goodwins et al, ${ }^{[11]} 2.3 \%$ \& Nagel et al, ${ }^{[21]} 10 \%$. Mortality at $\mathrm{pH}>7$ was seen in 2 studies only, Goldaber et al, ${ }^{[10]} 1.6 \%$ \& Vanderberg et al, ${ }^{[13]} 1.1 \%$. Similarly, we didn't find any death at $\mathrm{pH}$ above 7.0.

\section{Conclusion}

It is necessary to identify the babies, who will be at high risk for intrapartum hypoxia \& poor neonatal outcome, early death as a complication of asphyxia. We attempted to find the correlation of cord blood $\mathrm{pH}$ with birth asphyxia \& its effect on early neonatal outcome. A lower mean $\mathrm{pH}$ was observed in neonates who showed signs of fetal distress, need for resuscitation, need for resuscitation \& had poor neurological outcome, when compared to babies with a $\mathrm{pH}>7.1$. As umbilical cord $\mathrm{pH}$ is significantly associated with predicting the poor neonatal outcome such as need for resuscitation, NICU admission, seizures, encephalopathy \& early neonatal mortality, this study shows that pathological acidemia is observed at $\mathrm{pH}<7.10$ rather than $<7$ as suggested by AAP \& NNF and $<7.20$ as defined by ACOG. 


\section{References}

1. Lawn JE, Blencowe H, Oza S, You D, Lee AC, Waisawa P, et al. Every Newborn Study Group. Every Newborn: progress, priorities, and potential beyond survival. Lancet. 2014;384:189-205.

2. Sankar MJ, Neogi SB, Sharma J, Chauhan M, Srivastava R, Prabhakar PK, et al. State of newborn health in India. J Perinatol. 2016;36(S3):S3-S8. Available from: https://dx.doi. org/10.1038/jp.2016.183.

3. Sankar MJ, Natarajan CK, Das RR, Agarwal R, Chandrasekaran A, Paul VK. When do newborns die? A systematic review of timing of overall and cause-specific neonatal deaths in developing countries. J Perinatol. 2016;36(S1):S1S11. Available from: https://dx.doi.org/10.1038/jp.2016.27.

4. Sankar MJ, Neogi SB, Sharma J, Chauhan M, Srivastava R, Prabhakar PK. State of newborn health in India. J Perinatol. 2016;36(Suppl 3):S3-S8. Available from: https://dx.doi.org/ 10.1038/jp.2016.183.

5. Ghimire PR, Agho KE, Akombi BJ, Wali N, Dibley M, RaynesGreenow C. Perinatal Mortality in South Asia: Systematic Review of Observational Studies. Int J Environ Res Public Health. 2018;15(7):1428. Available from: https://dx.doi.org/ 10.3390/ijerph15071428.

6. Brown SD, Truog RD, Johnson JA, Ecker JL. Do differences in the American Academy of Pediatrics and the American College of Obstetricians and Gynecologists positions on the ethics of maternal-fetal interventions reflect subtly divergent professional sensitivities to pregnant women and fetuses? Pediatrics. 2006;117(4):1382-7. Available from: https://dx.doi. org/10.1542/peds.2004-2724.

7. Finer NN, Robertson CM, Richards RT, Pinnell LE, Peters KL. Hypoxic-ischemic encephalopathy in term neonates: Perinatal factors and outcome. J Pediatr. 1981;98(1):112-117. Available from: https://dx.doi.org/10.1016/s0022-3476(81)80555-0.

8. Sarnat HB, Sarnat MS. Neonatal encephalopathy following fetal distress. A clinical and electroencephalographic study. Arch Neurol. 1976;33(10):696-705.

9. Prasanna R, Karthikeyan P, Mani M, Paramanantham P, Sekar P. The strength of correlation between umbilical cord $\mathrm{pH}$ and early neonatal outcome. Int J Cont Pediatr. 2016;p. 134137. Available from: https://dx.doi.org/10.18203/2349-3291. ijcp20160145.

10. Goldaber KG, Gilstrap I, Lc, Lenovo KJ, Dax JS. Pathologic fetal acidemia. Obstet Gynecol. 1991;78(6):1103-1107.

11. Goodwin TM, Belai I, Hernandez P, Durand M, Paul RH. Asphyxial complications in the term newborn with severe umbilical acidemia. Am J Obstet Gynecol. 1992;167(6):15061512. Available from: https://dx.doi.org/10.1016/00029378(92)91728-s.

12. Andres RL, Saade G, Gilstrap LC, Wilkins I, Witlin A, Zlatnik F, et al. Association between umbilical blood gas parameters and neonatal morbidity and death in neonates with pathologic fetal acidemia. Am J Obstet Gynecol. 1999;181(4):867-871. Available from: https://dx.doi.org/10. 1016/s0002-9378(99)70316-9.
13. Vandenberg PP, Willianne N, Jongsma HW, Nijland R, Kolle AA, Nijhus J. Neonatal complications in newborns with an umbilical artery pH. Am J Obstet Gynecol. 1996;175(5):11521157. Available from: https://dx.doi.org/10.1016/s00029378(96)70021-2.

14. Ayres A. Predictive factors for neonatal morbidity in neonates with an umbilical arterial cord $\mathrm{pH}<7.00$. Am J Obstet Gynecol. 1998;178(4):872-3. Available from: https://dx.doi. org/10.1016/s0002-9378(98)70710-0.

15. Perlman JM, Risser R. Can asphyxiated infants at risk for neonatal seizures be rapidly identified by current high risk markers? Pediatr. 1996;97(4):456-62.

16. Mousaahmedpour-Kacho Y, Hagshenas M, Akbarianrad Z. Bahram Sadat Nasseri\& Ali Bijani. Short outcome of neonates born with abnormal umbilical cord arterial blood gases. Iran J Pediatr. 2015;25(3).

17. Victory R, Penava D, da Silva O, Natale R, Richardson B. Umbilical cord $\mathrm{pH}$ and base excess values in relation to adverse outcome events for infants delivering at term. Am J Obstet Gynecol. 2004;191(6):2021-2028. Available from: https://dx. doi.org/10.1016/j.ajog.2004.04.026.

18. Rogers KA, Ramalingam K. Use of umbilical cord blood gas analysis in the assessment of the newborn. Arch Dis Child Fetal Neonatal Ed. 2007;92(6):F430-F434. Available from: https://dx.doi.org/10.1136/adc.2006.099846.

19. Malin GL, Morris RK, Khan KS. Strength of association between umbilical cord $\mathrm{pH}$ and perinatal and long term outcomes: systematic review and meta-analysis. $\mathrm{Br}$ Med J. 2010;340(1):c1471-c1471. Available from: https://dx.doi.org/ 10.1136/bmj.c1471.

20. Yeh P, Emary K, Impey L. The Relationship Between Umbilical Cord Arterial $\mathrm{pH}$ and Serious Adverse Neonatal Outcome: Analysis of 51,519 Consecutive Validated Samples. Obstetric Anesthesia Digest. 2013;33(3):154-157. Available from: https://dx.doi.org/10.1097/01.aoa.0000432374.98570.01.

21. Naegel H, Vandenbussche FP, Oepkes, Dick HA, Jennekens SA, Laura A, et al. Follow up of children born with an umbilical arterial blood $\mathrm{pH}<7.00$. Am J Obstet Gynaecol. 1995;173(6):1758-1764.

Copyright: (C) the author(s), 2020. It is an open-access article distributed under the terms of the Creative Commons Attribution License (CC BY 4.0), which permits authors to retain ownership of the copyright for their content, and allow anyone to download, reuse, reprint, modify, distribute and/or copy the content as long as the original authors and source are cited.

How to cite this article: Singh N, Gupta AK, Arya AK. A Study on Correlation of Umbilical Cord Arterial Blood pH with Perinatal Asphyxia \& Early Neonatal Outcome. Asian J. Clin. Pediatr. Neonatol. 2020;8(2):30-35.

DOI: dx.doi.org/10.47009/ajcpn.2020.8.2.6

Source of Support: Nil, Conflict of Interest: None declared. 